\title{
Initial experience of SGLT2 inhibitor use in Type 2 Diabetes
}

\author{
B. Cooke, K. Ryan, M. Gormley, J.R. Lindsay
}

HSC) Belfast Health and Social Care Trust

Diabetes \& Endocrinology, Mater Infirmorum Hospital, Belfast Health \& Social Care Trust, Belfast, Northern Ireland, BT14 6AB.

\section{Background}

Sodium glucose co-transporter type 2 inhibitors (SGLT2) inhibitors offer a novel approach to glucose lowering in type 2 diabetes, based upon wider understanding of the kidney's role in glucose homeostasis. SGLT2 inhibitors decrease renal glucose reabsorption and results in enhanced urinary glucose excretion. ${ }^{1}$ Phase 3 clinical trials have demonstrated consistent glucose lowering effects and weight loss following SGLT2 inhibition. ${ }^{1}$

\section{Mode of action}
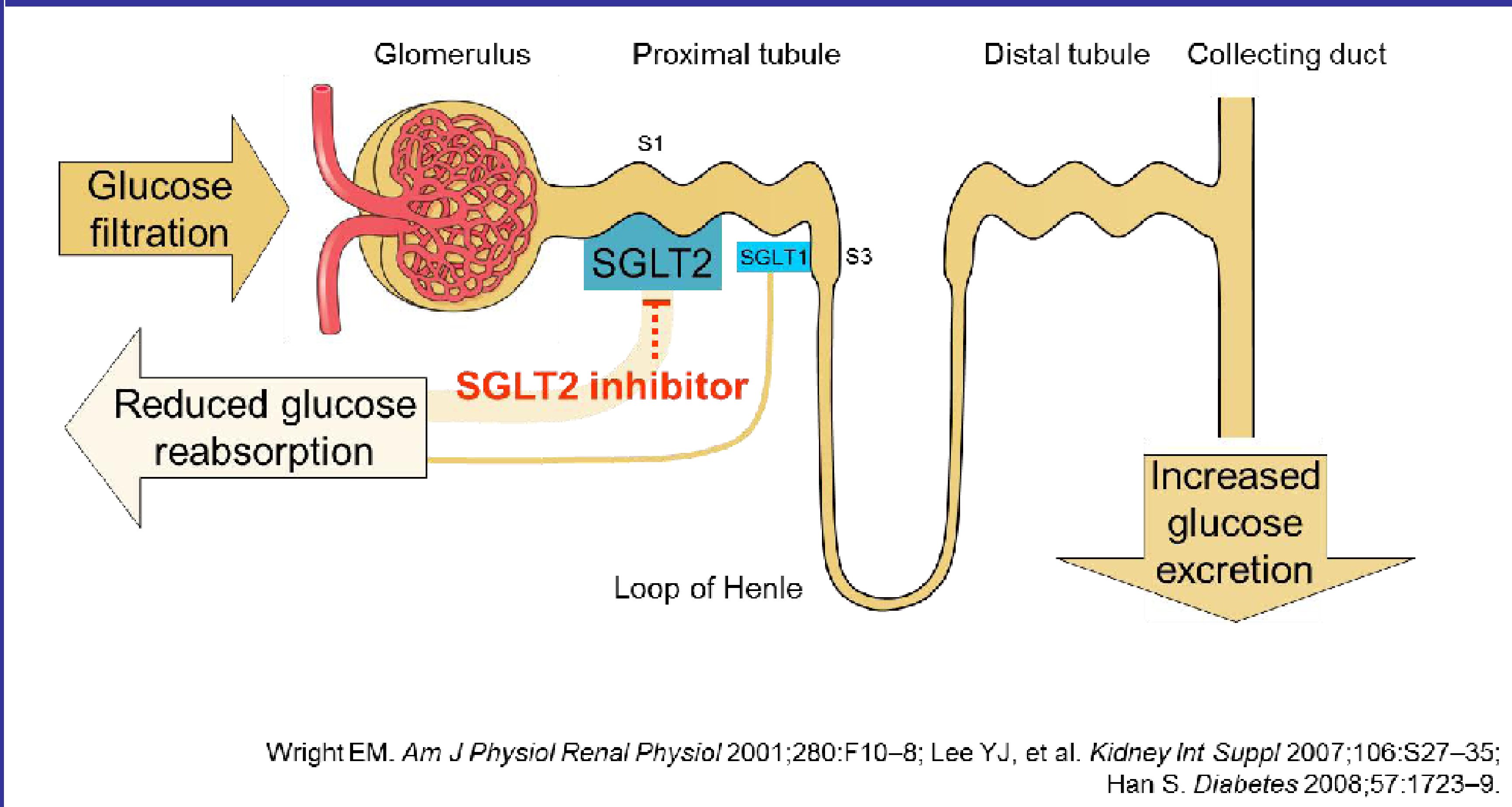

\section{Methods}

Patients attending diabetes clinic who had been treated with an SGLT2 inhibitor were identified. Data including age, gender, diabetes duration, baseline therapy and clinical parameters of $\mathrm{HbA}_{1 \mathrm{c}}$, weight, $\mathrm{BMI}$, renal function and blood pressure (BP) were collected retrospectively from a hospital database and laboratory system. Clinical parameters at treatment initiation and most recent clinic follow up were analysed.

\section{Demographics}

- Data from 34 patients $(23 \mathrm{M} / 11 \mathrm{~F})$ was analysed.

- Mean age 55.2 years (range 27-76 years).

- Mean diabetes duration of 9 years (range 0.9-26.8 years).

- Mean follow up period of 144 days. Median duration of SGLT2 inhibitor treatment of 123 days (range: 25-359 days)

-13 patients were treated with dual oral agents and 15 with insulin (16-540 units)

-Baseline therapies are demonstrated below.

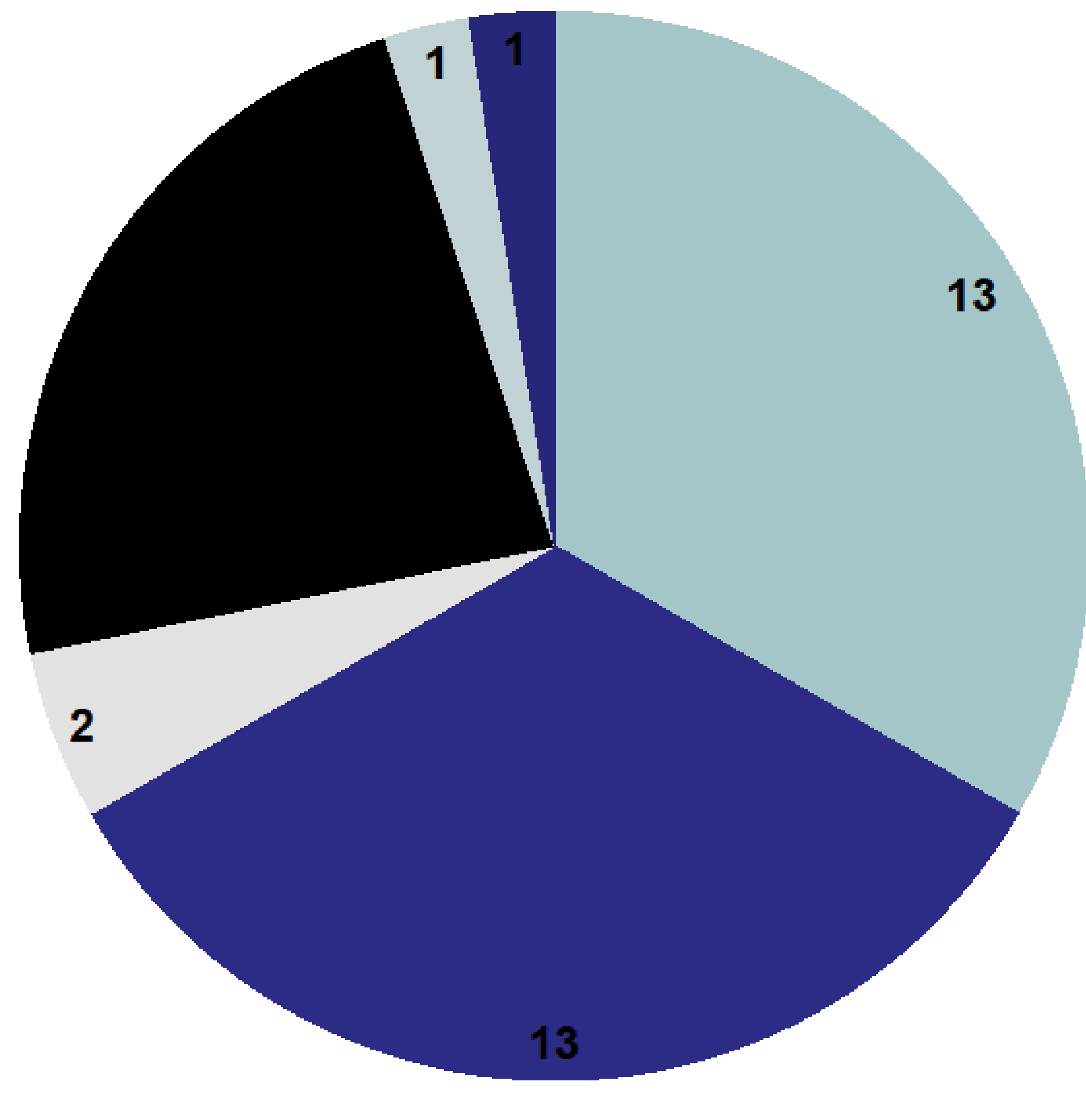

oral agents

oral agents and insulin

insulin

- oral agents and GLP-agonist

oral agents, GLP-agonist and insulin

- GLP-agonist

\begin{tabular}{|c|c|c|c|}
\hline \multicolumn{5}{|c|}{ RESULTS } \\
\hline $\begin{array}{c}\mathrm{HbA1c} \\
(\mathrm{mmol} / \mathrm{mol})\end{array}$ & 85.6 & 72.7 & $<0.01$ \\
\hline Weight $(\mathrm{Kg})$ & 105.3 & 102.6 & $<0.01$ \\
\hline $\mathrm{BMI}\left(\mathrm{Kg} / \mathrm{m}^{2}\right)$ & 36.1 & 35.2 & $<0.01$ \\
\hline $\begin{array}{c}\text { Systolic BP } \\
(\mathrm{mmHg})\end{array}$ & 130.4 & 126.9 & 0.31 \\
$\begin{array}{c}\text { Diastolic BP } \\
(\mathrm{mmHg})\end{array}$ & 76.5 & 72.8 & 0.08 \\
\hline
\end{tabular}

Significant improvements in glycaemic control (a) were observed in most cases with associated weight loss (b). There was a trend for reduction in diastolic blood pressure $(c, d)$.
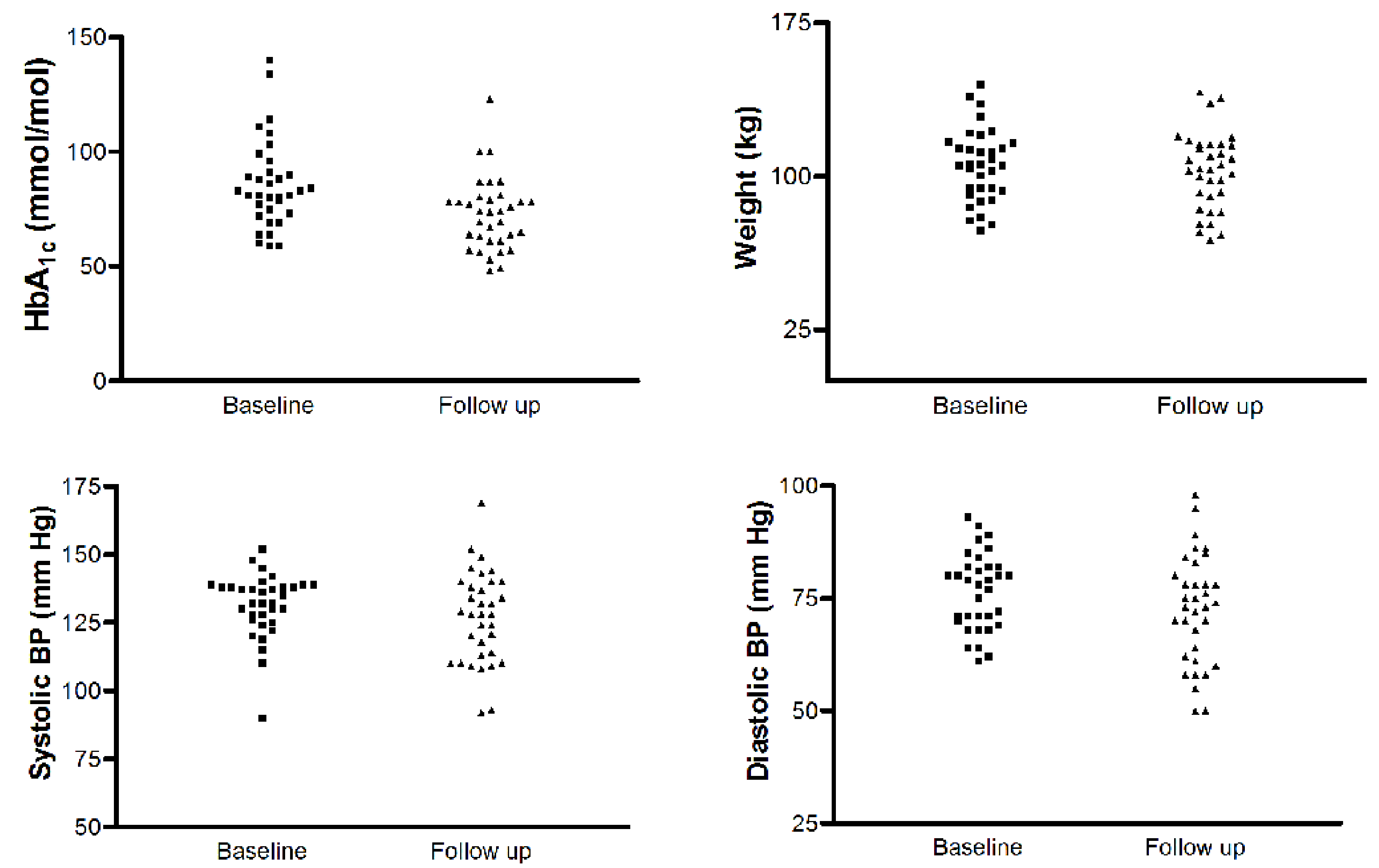

-Non responders were comparable to responders in terms of weight, age and duration of diabetes

- 1 patient discontinued treatment due to genital mycotic infections.

- 11 of 16 patients treated with insulin maintained a stable dose or achieved a dose reduction.

- Improvements in glycaemic control allowed for withdrawal of other aqents in 3 patients including prandial insulin in 1 individual

\section{NICE guidance}

Currently SGLT2 inhibitors are recommended by NICE in combination with metformin or insulin but not as triple therapy with a sulphonylurea and metformin. 10 of our patients were prescribed dapagliflozin as a triple oral agent. In 3 cases this was to delay injectable therapy -1 patient was a taxi driver and 2 others documented patient preference.

\section{Summary and conclusions}

This audit of our early experience with the SGLT2 inhibitor Dapagliflozin highlighted clinically meaningful and significant improvements in indices of $\mathrm{HbA}_{1 \mathrm{c}}$, weight and BMI. Only 1 patient in those surveyed was intolerant due to side effects. Longer term follow up for evidence of sustained drug efficacy is awaited.

\section{References}

1. Hasan FM et al. Diabetes Res Clin Pract.2014 Jun; 104(3):297-322

2. www.nice.org.uk 